\title{
El profesorado de Secundaria en España ante las políticas de rendición de cuentas en el marco de implantación de la LOMCE
}

\author{
Les enseignant(e)s du secondaire en Espagne face aux politiques \\ de reddition de comptes générées par la LOMCE \\ Secondary Teachers in Spain Facing the Policies of Accountability within \\ the frame of the Implantation of LOMCE
}

\author{
Mar Venegas, Elisa Usategui y Ana I. del Valle'
}

\begin{abstract}
Resumen
El objetivo de este artículo es analizar los discursos del profesorado de Secundaria Obligatoria (ESO) en España sobre las políticas de rendición de cuentas. El análisis se sitúa temporalmente en los primeros momentos de implantación en Secundaria de la LOMCE (2013), coincidiendo con la realización de los 10 grupos de discusión de los que proceden los datos. El análisis identifica tres grandes cuestiones: continuos cambios de legislación educativa en España durante el período democrático, e inestabilidad en las políticas educativas; consolidación de una cultura de la evaluación, destacando los estándares de aprendizaje; e impacto de estas tendencias sobre el profesionalismo docente, acentuando la rendición de cuentas del profesorado. Los datos permiten concluir que, a priori, todo el profesorado considera los cambios de legislación educativa solo de orden discursivo (político), sin generar un cambio ni estructural (en la organización de los centros), ni en las prácticas docentes. Sin embargo, un análisis minucioso deja ver que las reformas educativas recientes, especialmente la LOMCE, sí impactan sobre las prácticas docentes y la organización de los centros: se va consolidando una cultura de la evaluación cuyo principal mecanismo de regulación educativa son los dispositivos de rendición de cuentas, introduciendo cambios sobre la profesionalidad docente y para el alumnado. Se cuestiona la inmunidad del funcionariado en el marco de una nueva gobernanza, neoliberal, basada en la evaluación, como parte de cambios estructurales más profundos, que redefinen el profesionalismo docente, en lo que intervienen la burocratización del trabajo y la pérdida de autonomía del profesorado, como parte de una tendencia hacia la desprofesionalización del trabajo docente. La estrategia del profesorado es, en general, de resistencia, en la forma de reivindicación de su agencia como sujeto político que forme parte activa en los procesos educativos, al tiempo que empieza a internalizar el discurso de la responsabilización social del trabajo docente.
\end{abstract}

\section{Palabras clave}

Profesorado, Secundaria Obligatoria, políticas de rendición de cuentas, LOMCE, evaluación, profesionalismo .

\section{Résumé}

L'objectif de cet article est d'analyser les discours des enseignants de l'enseignement secondaire obligatoire en Espagne face aux politiques de reddition de comptes. L'enquête correspond aux premiers moments de l'introduction de la LOMCE (2013) dans le secondaire et s'appuie sur les données issues de 10 groupes de discussion. L’analyse identifie trois résultats majeurs: les changements continuels de la législation éducative en Espagne au cours de la période démocratique et l'instabilité dans les politiques éducatives; la consolidation d'une culture de l'évaluation, privilégiant les standards d'apprentissage; et l'impact de ces évolutions sur le professionnalisme enseignant, favorisant la reddition de comptes des enseignants. Les données permettent de conclure que, a priori, tous les enseignants considèrent que les changements dans la législation éducative sont seulement d'ordre discursif (politique) sans générer un changement ni de la structure (organisation des écoles) ni des pratiques d'enseignement. Cependant, une analyse minutieuse révèle que les réformes éducatives récentes, en particulier la LOMCE, ont un impact sur les pratiques éducatives des enseignants même dans l'organisation des écoles: une culture de l'évaluation est en train de se consolider dans laquelle les dispositifs de reddition de comptes constituent le mécanisme principal de régulation éducative, ce qui introduit des changements sur le professionnalisme des enseignants et pour les élèves. L'immunité des fonctionnaires est mise en question en vertu d'une nouvelle gouvernance, néo-libérale, fondée sur l'évaluation, dans le cadre des changements structurels profonds qui redéfinissent le professionnalisme des enseignants. Ces changements concernent la bureaucratisation du travail et la perte d'autonomie des enseignants, dans le cadre d'une tendance à la dé-professionnalisation du travail enseignant. La stratégie des enseignants est de l'ordre de la résistance sous la forme de la revendication de leur capacité en tant que sujets politiques à participer activement aux processus éducatifs, cependant qu’ils commencent à internaliser le discours de responsabilité sociale du travail enseignant.

1 Mar Venegas (Universidad de Granada, España), Elisa Usategui y Ana I. del Valle (Universidad del País Vasco, España). 


\section{Mots-clés}

Enseignant(e)s, enseignement secondaire, évaluation, LOMCE, professionnalisme, reddition de comptes.

\section{Abstract}

The objective of this paper is to analyse the Compulsory Secondary Education Teachers' discourses facing the policies of accountabilityin Spain.The analysis is located temporarily in the first moments of implantation of LOMCE (2013) in Secondary Education, coinciding with the realisation of the 10 discussion groups from which the data come. The analysis identifies three major issues: continuous changes in educational legislation in Spain during the democratic period and instability in educational policies; the consolidation of a culture of evaluation, highlighting learning standards; and the impact of these trends on teacher professionalism, emphasising teacher accountability. The data allow us to conclude that, a priori, all teachers consider changes in educational legislation only at the discursive (political) level, without generating any change either structural (in the centres' organisation) or in teachers' practices. However, a meticulous analysis shows that recent educational reforms, especially the LOMCE one, do have an impact on both teachers' practices and the centres' organisation: an evaluation culture is being consolidated whose main mechanism of educational regulation is the devices of accountability, introducing changes on both teacher professionalism and for students. The immunity of civil servants is questioned within the framework of a new, neoliberal, evaluation-based, governance, as part of deeper structural changes, which redefine teacher professionalism, involving the bureaucratisation of work and the loss of teacher autonomy, as part of a de-professionalising tendency of the teaching work. The teachers' strategy is resistance, in the form of vindication of their agency as political subjects to form an active part throughout the educational processes, while they begin to internalise the discourse of the social responsibility of the teaching work.

\section{Key words}

Teachers, compulsory secondary education, accountability policies, LOMCE, evaluation, professionalism.

\section{Introducción}

Desde los años 70, se ha ido asentando un nuevo modelo degestión de lo público, de orientación neoliberal, conocido en español como Nueva Gestión Pública (NGP), que va consolidando un Estado evaluador (Neave, 1999, cf. Maroy y Voisin, 2013) y una regulación post-burocrática (Maroy, 2008), en que la política educativa se define en base a (Hall y McGinity, 2015):

1. Cuasi-mercados educativos locales, donde se establecen rankings entre los centros educativos para competir por sus clientes, propio de una privatización educativa creciente ${ }^{2}$.

2. Tests nacionales, como parte de una agenda de estándares educativos (véase también Cattonar, Dumay y Maroy, 2013), de modo que las evaluaciones externas promueven, entre otras cosas, cambios en la profesionalidad docente (Maroy, 2006). La evaluación deviene, así, un dispositivo central de regulación del sistema educativo (Mons, 2009) y de una nueva gobernanza (Martuccelli, 2010).

Estos cambios en la política educativa persiguen mejorar la eficiencia y eficacia educativas, reducir la desigualdad y aumentar la equidad entre el alumnado (Maroy y Voisin, 2013). En España, las dos últimas leyes educativas orgánicas, LOE (2006) y LOMCE (2013), van en esta dirección: autonomía de los centros, evaluación externa y rendición de cuentas; pero es la LOMCE la que materializa un profundo giro hacia una política educativa abiertamente neoliberal (Bonal, 2014), imponiendo con fuerza estándares y resultados de aprendizaje evaluables (Martínez, 2014).

En este sentido, la investigación reciente enfatiza la responsabilidad del profesorado (individual y colectivamente) en el éxito del alumnado, lo que le sitúa en el centro de las políticas educativas cada vez

2 Para un análisis en profundidad de estos procesos, véase el monográfico de la RASE coordinador por Xavier Bonal y Antoni Verger (2016). 
más (Dumay y Dupriez, 2009, cf. Dutercq y Maroy, 2017; López, 2013). De ahí la rendición de cuentas del profesorado según dos tipos de políticas (Mons, 2009; Maroy y Voisin, 2013): de accountability, cuya lógica es que, en el marco dela NGP, se introduce la accountability, cuyo dispositivo principal de gestión es la evaluación de los resultados (la performatividad), sobre los que se establecen medidas para la asignación tanto de recursos como de salarios (Mons, 2009); y de responsabilización, mediante dispositivos de responsabilización, tales como políticas de evaluación externa, de desarrollo profesional, de formación del profesorado o de apoyo a la innovación pedagógica (Dutercq y Maroy, 2017), sin implicar mecanismos de accountability ligados a los resultados educativos (Maroy y Voisin, 2013; Dutercq y Maroy, 2017).

Junto a evaluación y rendición de cuentas, la tercera dimensión clave en este marco educativo es la propia profesión docente. La sociología de los años 50-60, funcionalista, definía una profesión en base a (Whitty, 2000):

- el uso de habilidades basado en el conocimiento teórico,

- la formación en esas habilidades certificadas mediante examen,

- un código de conducta profesional orientado hacia el 'bien público',

- y una organización profesional poderosa.

Así pues, la profesionalización se define como el intento de hacerse con las características asociadas a una profesión (Whitty, 2000). Sin embargo, las reformas educativas de las últimas décadas introducen el debate sobre la proletarización, así como sobre la desprofesionalización vs. reprofesionalización de la profesión docente, que Whitty considera una lucha entre versiones del profesionalismo docente en el siglo XXI, pasando de una autonomía regulada a una situación en que el profesorado está sujeto a las derivas del mercado, y mayor control y vigilancia por parte del Estado evaluador (Neave, 1988, cf. Witty, 2000). El profesionalismo docente hace referencia a las estrategias y retóricas utilizadas por los miembros de una ocupación determinada para mejorar su estatus, salario y condiciones, mientras que la profesionalidad docente se refiere a los conocimientos, habilidades y métodos seguidos por el profesorado en el proceso de enseñanza (Hoyle, 1974, cf. Witty, 2000), definición similar a la presente en las investigaciones francófonas (Perez-Roux, 2012, cf. Dutercq y Maroy, 2017). Por su parte, en sus trabajos recientes, Julia Evetts (2006, 2011) diferencia entre profesionalismo ocupacional y profesionalismo organizacional, concluyendo que existe un retroceso del profesionalismo en beneficio de un reforzamiento de la organización burocrática.

En este escenario de fragmentación en las profesiones, hay miembros que adoptan los cambios con entusiasmo, mientras otros se resisten abiertamente a ello (Hanlon, 1998, cf. Witty, 2000). Así lo observan también Hall y MacGinity (2015) entre el profesorado inglés, cuyo profesionalismo aparece ligado a una conformidad que, sin embargo, es adaptativa o flexible, pues comprende también resistencia (personal o profesional), como única opción para mantener una identidad profesional viable frente a un neoliberalismo agresivo. En línea con Evetts $(2006,2011)$ y Whitty (2000), también Hall y McGinity (2015) se refieren a dos momentos/modelos de profesionalismo docente: «bureau professionalism (Clarke \& Newman, 1997) in which teachers were granted a licensed autonomy (Dale, 1989) exerting significant control over aspects of their work» (p.4) que, debido a «concerns about the de-professionalization, proletarianization (Lawn $60 \mathrm{Og}$ a, 1988) and post-professionalism (Ball, 2003)» (p.4) entre el profesorado, hacen que profesionalismo y neoliberalismo sean antagónicos, pues el primero impide al segundo perseguir la eficiencia propia de la lógica de merca- 
do, de manera que, según Hall y McGinity (2015), el profesorado se encuentra en un momento de fuerte redefinición del trabajo y el profesionialismo docentes: «our data reveals the emergence of a NPM professionalism in schools in England tied closely to prevailing marketized, metricized and managerialist practices in schools in this contexts (Hall y McGinity, 2015: 11). Esta misma tesis es defendida también por Dutercq y Maroy (2017) para el contexto francófono.

En otro lugar, nos preguntamos si el trabajo de orientación del profesorado de Secundaria en España puede ser considerado como una práctica educativa de responsabilización social (Venegas, 2017a). Como contribución a este monográfico, y en el marco de esa misma investigación ${ }^{3}$, el objetivo de este artículo es analizar los discursos del profesorado de Secundaria Obligatoria (ESO $)^{4}$ en España sobre las políticas de rendición de cuentas del trabajo docente. El análisis se sitúa temporalmente en los primeros momentos de implantación en Secundaria de la ley educativa más reciente, y en vigor, la LOMCE (2013) ${ }^{5}$, que coincide en el tiempo con la fase de realización de los grupos de discusión de la investigación. Los datos muestran tres grandes aspectos relativos al objeto analizado:

- continuos cambios de legislación educativa en España durante el período democrático (desde 1978 hasta la actualidad), y una consecuente falta de estabilidad en las políticas educativas;

- consolidación creciente, mediante esos cambios, de una cultura de la evaluación, destacando los estándares de aprendizaje como dispositivo principal;

- e impacto de estas tendencias sobre el profesionalismo docente, destacando la exigencia creciente de rendición de cuentas del trabajo docente.

Este artículo da cuenta de todo ello.

\section{Metodología de la investigación}

La investigación de la que procede este artículo comprende dos fases, una cualitativa, mediante la técnica del grupo de discusión, y una cuantitativa, mediante la técnica de la encuesta. Dado que su objetivo es analizar los discursos del profesorado, este artículo se centra en la fase cualitativa, consistente en diez grupos de discusión, correspondientes a las diez Comunidades Autónomas (CCAA) españolas que han participado en la investigación (de las diecisiete que hay en total): Comunidad de Madrid, Andalucía, País Vasco, Comunidad de Murcia, Comunidad Valenciana, Castilla y León, Islas Baleares, Islas Canarias, La Rioja y Navarra. Los grupos se han realizado con profesorado que imparte docencia en ESO.

En la investigación, se optó, para la primera fase, por la técnica del grupo de discusión porque parecía la más ajustada a su objetivo general: conocer, a través de los discursos docentes, las representaciones sociales y culturales que subyacen al trabajo de orientación del profesorado según el contexto socioeconómico, por lo que la unidad territorial de referencia han sido las CCAA. Las preguntas del protocolo de los grupos han girado, pues, en torno a esta cuestión.

Sin embargo, es importante señalar que, seguramente por coincidir temporalmente la realización de los grupos con la implantación de la LOMCE en Secundaria, en los discursos del profesorado de la in-

3 Los datos de este artículo proceden del proyecto «Contexto socieconómico y orientación educativa y profesional del profesorado de Secundaria» (Referencia CSO2013-47168-R), Ministerio de Economía y Competitividad del Gobierno español (2013-2016).

4 Profesorado que trabaja con el alumnado de $1^{\circ}$ a $4^{\circ}$ ESO, que está entre 12-16 años, si cumple con su curso "natural", es decir, toda la Secundaria Obligatoria.

5 Cursos $1^{\circ}$ y $3^{\circ}$ de ESO: implantación en el curso escolar 2015-2016.Cursos $2^{\circ}$ y $4^{\circ}$ de ESO: implantación en el curso escolar $2016-2017$. 
vestigación se hace presente una discusión que consideramos sociológicamente significativa de los temas que preocupan al profesorado en el momento actual: se trata de la rendición de cuentas que la LOMCE impone sobre el trabajo docente. Es en esa coyuntura donde radica el origen de este artículo, en el marco de una investigación que no estudia específicamente las políticas de rendición de cuentas dirigidas al profesorado.

En España, cada CCAA es un distrito educativo único, con las competencias educativas descentralizadas a este nivel administrativo y territorial. Así, cualquier docente de la red educativa pública que aprueba un examen de oposición suele trabajar en diversos centros públicos de una misma CCAA a lo largo de su carrera profesional, por lo que su experiencia supone un conocimiento amplio de la CCAA, incluyendo zonas rurales y urbanas, diferentes municipios y provincias, etc. Los datos producidos en los grupos de esta investigación confirman este hecho, por lo que, si bien la técnica del grupo de discusión no busca la representatividad estadística, cabe afirmar que los datos procedentes de los diez grupos de esta investigación arrojan una imagen bastante completa de los discursos del profesorado de Secundaria Obligatoria en el momento actual en España.

Para seleccionar a los miembros de los grupos, 63 sujetos en total, se ha seguido el criterio de la heterogeneidad, en función de las variables y la distribución que muestra la siguiente tabla ${ }^{6}$ :

Tabla I. Criterios y perfil de composición de los grupos discusión en datos porcentuales (\%)

\begin{tabular}{|c|c|}
\hline VARIBLE & DISTRIBUCIÓN \\
\hline \multirow{2}{*}{ Sexo } & 50,8 mujeres \\
\hline & 49,2 hombres \\
\hline \multirow{3}{*}{ Área de conocimiento } & 46 de Letras \\
\hline & 39,7 de Ciencias \\
\hline & 14,3 de otras especialidades \\
\hline \multirow{3}{*}{ Tipo de contrato } & 60,3 funcionarios \\
\hline & 36,5 contratados laborales \\
\hline & 3,2 interinos \\
\hline \multirow{3}{*}{ Años de experiencia } & 46 con más de 20 años \\
\hline & 28,6 con entre $10-20$ años \\
\hline & 25,4 con menos de 10 años \\
\hline \multirow{3}{*}{ Tipo de titularidad del centro } & 63,5 públicos \\
\hline & 33,3 concertados \\
\hline & 3,2 privados \\
\hline \multirow{5}{*}{ Oferta educativa del centro ${ }^{7}$} & I-P-ESO: 3,2 \\
\hline & I-P-ESO-B: 1,6 \\
\hline & I-P-ESO-B-FP: 3,2 \\
\hline & P-ESO: 7,9 \\
\hline & P-ESO-B: 12,7 \\
\hline
\end{tabular}

6 Estos datos son relativos al centro en que se encuentra el o la docente en el momento de hacer los grupos.

7 I: Infantil, P: Primaria, ESO: Educación Secundaria Obligatoria, B: Bachillerato, FP: Formación Profesional. 


\begin{tabular}{|c|c|}
\hline VARIBLE & DISTRIBUCIÓN \\
\hline \multirow{4}{*}{ Oferta educativa del centro } & P.ESO-B.FP: 4,8 \\
\hline & ESO: 9,5 \\
\hline & ESO-B: 39,7 \\
\hline & ESO-B-PP: 17,5 \\
\hline \multirow{8}{*}{ Nivel socioeconómico del alumnado asistente al centro } & Baio 17,5 \\
\hline & Medio baio 7,9 \\
\hline & Medio 11,1 \\
\hline & Mixto 12,7 \\
\hline & Medio alto 11,1 \\
\hline & Alto 3,2 \\
\hline & Elevada inmigración $1,6^{8}$ \\
\hline & NS/NC 34,9 \\
\hline
\end{tabular}

Fuente: Elaboración propia.

Aunque solo hay diez comunidades autónomas participantes, hay once grupos. El G1 (Madrid) fue piloto, por lo que se repitió en último lugar. G1 y G11 se realizaron en Madrid. Aquí solo se ha analizado el G11. La tabla del Anexo 1 identifica los sujetos a quienes pertenecen los verbatims que ilustran el análisis del artículo, por orden de aparición en el apartado 3; para ello, se sigue un código en que la G es Grupo, el número indica la Comunidad Autónoma por orden de realización, H es Hombre y M es Mujer, el último número se les ha asignado según la posición que ocuparan en la mesa, al contrario de las agujas del reloj.

Los grupos han sido realizados entre abril y noviembre de 2015. Han sido grabados y transcritos. El análisis se ha hecho con la ayuda del software para análisis cualitativo Nudist Nvivo 11. Al analizar los grupos, se han categorizado de forma espontánea los datos relativos a los discursos de estos 10 grupos y 63 docentes de ESO sobre las políticas de rendición de cuentas en España, dando lugar a las categorías de dimensiones de análisis que se explican en el siguiente apartado.

\section{Análisis de los datos}

Antes de comenzar este análisis, es necesario recordar que los datos de este artículo no proceden de una investigación cuyo objetivo son las políticas de rendición de cuentas del profesorado de Secundaria en España. Los datos que se analizan emergen en los discursos de los grupos de discusión de esta investigación de forma espontánea, lo que nos ha llevado a reparar en la importancia (educativa, social y sociológica) que, para el profesorado de la investigación, tiene la implantación de políticas de rendición de cuentas en España en el momento de hacer los grupos de discusión, lo que, como señalamos antes, coincide con la implantación de la LOMCE en Secundaria Obligatoria.

Situándonos en este hecho, central para el análisis de los datos, los discursos de este profesorado relativos a las políticas de rendición de cuentas en España (la LOMCE, principalmente) señalan tres grandes dimensiones:

8 El 1,6\% del profesorado no señala el nivel socioeconómico de su alumnado sino estar en un centro con un nivel elevado de inmigración. Esos datos porcentuales se refieren, pues, al profesorado que señala cada nivel del alumnado de su centro. 
- los continuos cambios de legislación educativa en España durante el período democrático (19782017);

- la evaluación del alumnado y los estándares de aprendizaje;

- y el impacto de estas tendencias sobre la rendición de cuentas del profesorado y sobre el profesionalismo docente.

La figura 1 muestra la presencia de referencias existentes para cada una de estas tres dimensiones sobre el total de datos de los grupos referidos a la rendición de cuentas del profesorado:

\section{Figura 1. Las tres dimensiones en torno al profesorado y la rendición de cuentas}

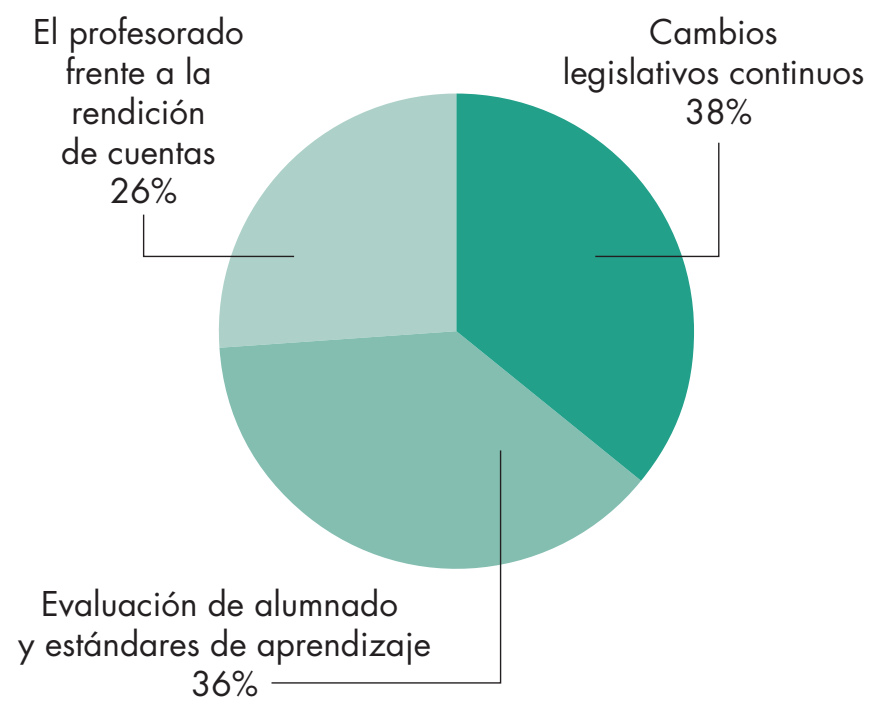

Fuente: Elaboración propia.

\section{1. Cambios continuos en la legislación educativa española}

En su discurso sobre las políticas de rendición de cuentas en España, el profesorado de la investigación contextualiza este aspecto en un marco de referencia más amplio, que representa un nivel mesosociológico de análisis, como es el de la legislación educativa española, en general, desde el comienzo de la democracia (1978), enfatizando, con absoluta unanimidad en los discursos, su falta de estabilidad (sobre esta cuestión, véase De Puelles, 2016). Este fenómeno da forma al resto de dinámicas y procesos sobre política educativa en España. Ello se debe, según muestran los datos, a la manipulación política cada vez que cambia el gobierno estatal, lo que despierta las críticas y el escepticismo del profesorado de la investigación sobre el valor de las reformas educativas:

«De la Educación siempre hace bandera cualquier gobierno (...) Y creo que cualquier ley, sobre todo de tipo educativo, necesita muchos años de rodaje. Y creo que en este país se ha dicho por activa y por pasiva: mientras no baya un gran consenso a nivel politico, esto no va a salir adelante. (...) Lo que no puede ser es que cada vez que cambia el gobierno cambia la Ley de Educación». (G4H1)

"Casi no me sé una [ley educativa], ahora paso a otra. Y, sobre todo, esa sensación de inestabilidad que tienes, y que los alumnos también tienen». (G11H2) 
«Muchos de mis compañeros dicen "no me he estudiado en profundidad la LOMCE porque seguro que en el dos mil..., cuando entren éstos (...) va a haber otra [ley educativa]”». (G6M1).

La figura 2 muestra las subcategorías que emergen en los discursos docentes al analizar los continuos cambios de legislación educativa en España:

\section{Figura 2. Subcategorías relativas a los continuos cambios de legislación}

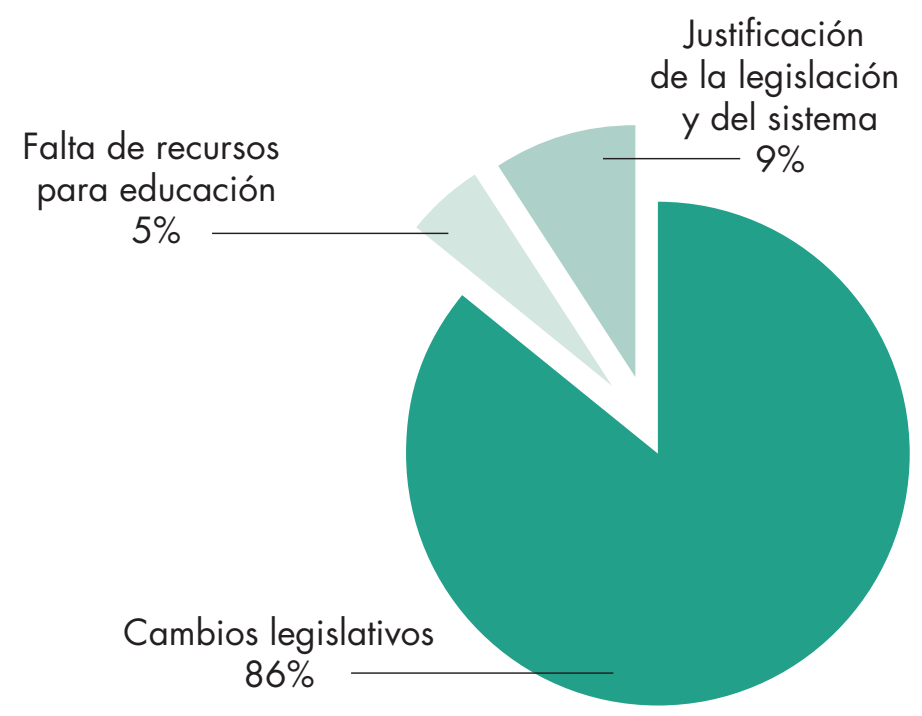

Fuente: Elaboración propia.

La opinión unánime del profesorado de la investigación es que los cambios son, en su práctica totalidad, de orden discursivo (político), pero no generan un cambio ni estructural ni en las prácticas docentes, porque no ofrecen directrices claras desde arriba sobre cómo concretar esos cambios legislativos en la práctica docente y la organización de los centros. El resultado es una situación intermedia, digamos una estrategia de acomodación del profesorado, que intenta asumir las pautas de la nueva legislación pero que, en el fondo, sigue la inercia de lo que hacía con anterioridad. No se observa una resistencia abierta en este sentido, sino, más bien, el reconocimiento de que, al final, todo sigue más o menos igual:

«Yo creo que al final se traduce en que no cambia nada porque en realidad al final todos hacemos lo que podemos». (G9M4).

«El cambio de nomenclatura, nadie sabe lo que son los estándares, ni siquiera la inspectora. Y es como si todo al final es el mismo perro con diferente collar». (G11H2).

«El que nos impongan la ley como nos la han impuesto este año, que tenemos que programar sin que los curriculums estén establecidos, (...) a contrarreloj. Empiezan las clases pero no tenemos la ley en la que nos basamos para empezar el curso. (...) Ni libros, no tenemos medios. (...) la legislación también debe de ir un poco más lenta en ese sentido o tomarse su tiempo para aplicarla». (G8M1)

El resultado es, según algunos/as docentes, que estos vaivenes en las políticas educativas «lo que bacen es empeorar la imagen de la escuela» (G7H1), incluso «dejan generaciones perdidas (... porque) no se puede terminar de crear una asignatura, unos conocimientos, porque todo el tiempo está cambiando». (G7M3). 
Por otro lado, también hay quien sostiene una visión más estructuralista, al considerar que la falta de mejora no es tanto por las continuas reformas educativas, cuanto por la inercia del propio sistema educativo a reproducirse:

"Yo creo que el sistema educativo hace lo que puede y creo que no puede hacer más (...) aunque cambiemos el sistema varias veces yo creo que la inercia va a seguir igual》. (G10H3).

Algunos/as docentes explican el motivo de esta tendencia reproductora: la falta de recursos que el gobierno español destina a educación y que serían necesarios para acometer los cambios:

«No podemos pretender que la enseñanza en España dé respuesta a todo lo que se le pide cuando cada vez se le da menos dinero». (G4H1).

Así pues, aunque la opinión es unánime sobre la inestabilidad educativa derivada de las continuas reformas en España, hay divergencias entre el profesorado sobre si la falta deimpacto de los cambios discursivos (de leyes) en la estructura (organización de los centros) y las prácticas (docentes) del sistema educativo español se debe, bien a la falta de directrices de las leyes para modificar la estructura y las prácticas del sistema educativo, o bien a la tendencia del propio sistema educativo a reproducirse, sobre todo por falta de recursos que hagan posible un cambio a mejor.

\subsection{Evaluación del alumnado y estándares de aprendizaje}

La introducción paulatina de estándares de aprendizaje es uno de los dispositivos que los cambios de legislación educativa van poniendo en marcha para regular los resultados del sistema educativo español (Luengo y Saura, 2013). Así, los llamados «estándares de aprendizaje» introducidos por la LOMCE (Martínez, 2014), y conducentes a una cultura de la evaluación (Ruiz, 2010), ocupan el segundo aspecto más citado en los grupos de discusión de esta investigación con respecto a las políticas de rendición de cuentas, una tendencia creciente en las sociedades (Martuccelli, 2010) y los sistemas educativos occidentales (Feito, 2017). La figura 3 muestra los temas presentes en este segundo aspecto, y la presencia relativa de los mismos en los grupos de discusión.

\section{Figura 3. Subcategorías relativas a la evaluación del alumnado y los estándares de aprendizaje}

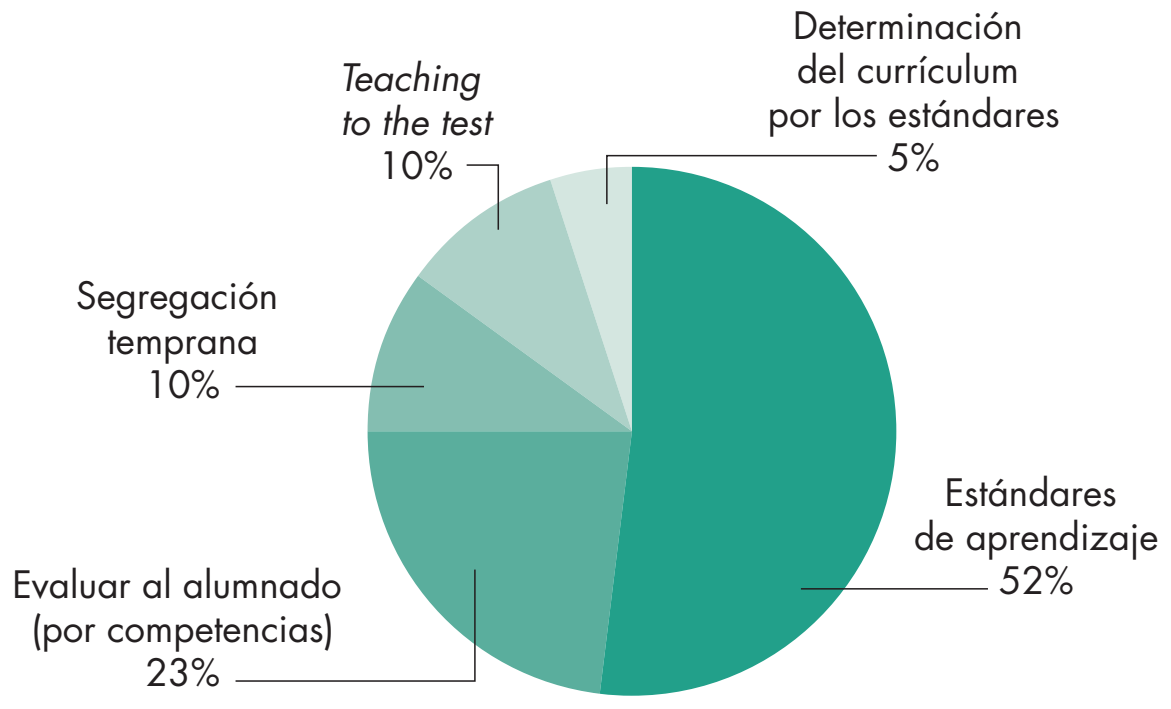

Fuente: Elaboración propia. 
El aspecto más presente en los discursos del profesorado de esta investigación sobre evaluación es la introducción de estándares de aprendizaje, que comparte la falta de directrices, por parte de la administración educativa, de que adolece la implantación de nuevas leyes educativas en general, por lo que, de nuevo, los datos muestran que la estrategia del profesorado es la de una acomodación a medio camino entre la adaptación a los cambios legislativos y la reproducción de sus prácticas anteriores a esos cambios:

"Los estándares de aprendizaje (...) dejan al profesorado con la tarea de: "Bueno, abi tienes los Estándares y de aqui en adelante te buscas la vida y a ver cómo los pones en marcha". (...) Yo creo que ahi si que hay un poco de esquizofrenia en saber exactamente qué pedimos a nuestros chicos, y en base a qué evaluamos el éxito de una persona». (G6H3).

«Muchos compañeros míos con los estándares, lo que es calificar a los alumnos con un criterio que no sea el aprobado y el suspenso, pues estamos que no sabemos cómo concretarlo». (G4H2).

«En los propios estándares que tenemos (...) sabemos que tenemos que evaluar en base a eso pero luego, a la hora de la realidad, yo creo que los criterios van a ser los de tú a tú». (G4H4).

De ahí que haya quienes piensan que el Ministerio de Educación debería acompañar al profesorado en la asimilación del nuevo modelo de trabajo docente impuesto por la LOMCE, y dar estabilidad al sistema:

«Si el Ministerio tiene preocupación porque cambien las cosas (...) tiene que ilusionar a su personaly explicarle el cambio. (...) Como ha babido tantos cambios, yo creo que bay un escepticismo por parte de todo el mundo, que no le da importancia a que ahora se llamen "estándares de aprendizaje", porque piensa que dentro de seis meses o un año va a aparecer otra cosa ». (G4H5).

El profesorado de la investigación señala la falta de recursos, también, para la adopción del modelo de evaluación estandarizada, destacando especialmente el problema de la elevada ratio docente/ estudiantes:

«Lo que no podemos pretender es evaluar por estándares, o querer hacer proyectos, cuando tienes aulas masificadas con treinta y tantos o cuarenta alumnos. (...) ¿Cómo voy a manejar yo 150 estándares de cada alumno si no tengo tiempo, si es imposible? (...) Queremos tener leyes como los países más avanzados según el Informe PIS A, pero luego no damos medios, y eso no puede ser». (G4H1).

La opinión mayoritaria entre el profesorado de la investigación, marcada por la controversia, queda perfectamente ilustrada por las palabras de este docente:

"Una sugerencia yo la tengo clara, y todos aqui, me parece: el no cargarle con cosas que tenemos siempre la duda de la efectividad sobre la enseñanza, es decir, los estándares. No sé si estoy a favor o en contra, pero está claro que hay determinadas cosas burocráticas que sí, que seguro que yendo a esas leyes pues lo hacen con muy buena intención y sobre el papel todo es estupendo, pero quiero decir, son cosas tan irreales que todo eso lo que hace es desviarnos de otras cosas más importantes que es prepararse bien la clase, poder conocer a los alumnos...». (G4H3).

En definitiva, aunque aparentemente no hay, según hemos visto en el discurso del profesorado de la investigación, un impacto directo de los cambios de leyes educativas sobre la organización de los 
centros y las prácticas del profesorado, debido a la falta de sistematización de directrices que hagan posible la implementación de esos cambios legislativos, sin embargo, un análisis más fino y detallado de esos discursos muestra cómo la política de rendición de cuentas del trabajo docente va introduciendo modificaciones profundas sobre la profesionalidad docente (Maroy, 2006), como vamos a mostrar a continuación.

Los datos muestran dos efectos perversos en este sentido. El primero es lo que la literatura llama «teaching to the test» (Mons, 2009; Yerly, 2017) ${ }^{9}$, esto es, enseñar para pasar las pruebas externas objetivables con los mejores resultados posibles, que son, en definitiva, no sólo los resultados del alumnado al que se evalúa, sino también del profesorado que lo ha formado:

«Tenemos una mochila muy pesada que se llama pruebas externas, que se llaman pruebas de acceso a selectividad, a universidades, que nos pautan mucho la forma de trabajar». (G10H2).

«No se puede bablar de competencias, de trabajo colaborativo, cuando después tienes que pasar una prueba (... Pues) entrenamos el tipo test y nos olvidamos de las tonterías». (G5H4).

"A mi lo que me interesa es darte los polinomios y ya está, porque va a la selectividad, y que saques un siete para no quedar yo mal, para no saber que soy mal profesor». (G3H2).

Como consecuencia de lo anterior, el segundo efecto perverso es la reducción del currículum a los contenidos relacionados con esos estándares (Mons, 2009; Yerly, 2017):

«En la LOMCE, además, yo creo que nos hace mucho daño (...) la necesidad de obtener resultados positivos en pruebas objetivables (... Mientras que) otros aspectos que a mi me parecen tan relevantes (...) no se preguntan en ningún sitio». (G6H3).

Frente a esos efectos perversos, buena parte del profesorado reivindica la dimensión humana de esa relación docente que es el proceso de enseñanza-aprendizaje, que no puede ser medida a través de los estándares, pero que sigue dignificando el trabajo docente, como señala una de las profesoras de la investigación:

«Nos encontramos con valoraciones externas luego, de nuestro trabajo, que no saben..., que vienen a hacer unos exámenes. ¿Por qué? Porque no pueden venir a hacer una valoración externa de cuál ha sido la evolución humana de esa futura persona adulta y madura. Porque claro, ¿cómo se puede medir en un test el compañerismo, el trabajo en equipo, la madurez. emocional, que ha estado de moda una temporada, o el pensamiento crítico? (...) Tenemos que encontrar el equilibrio». (G9H1).

El segundo aspecto más presente en los discursos de este profesorado sobre evaluación es la evaluación del alumnado por competencias que, según el profesorado, tampoco se le ha explicado sistemáticamente, para que pueda incorporarlo a sus prácticas docentes:

«Los preámbulos de todas las leyes, de la LOMCE, de la LOE, te dicen claramente cuál es nuestro papel ahora mismo como educadores y te dicen que tenemos que trabajar y evaluar por competencias. Abi está el gran reto, que se queda abí. Hablamos de competencias pero nadie dice "sí, las evalúo, ¿cómo?"》. (G10M3).

9 Este fenómeno es citado también por Maroy, Mathou y Vaillancourt en este mismo monográfico. 
Una respuesta minoritaria del profesorado a la centralidad de la evaluación al alumnado se formula en términos de rechazo, por entender que determina excesivamente la 'producción de los sujetos escolares’ (Dubet y Martuccelli, 1998), homogeneizándola:

"Yo diría que es totalmente contraproducente el evaluarles directamente. Contra más pequeños, todavía peor. ¿Por qué? Porque estamos marcando qué motivación van a tener (...) creo que la evaluación es uno de los lastres grandes, grandes que tenemos. (...) este modelo te pide una, premia a un tipo de persona». (G3H1).

En relación con la evaluación de los resultados del alumnado, emerge uno de los aspectos más cuestionados socialmente en la LOMCE en ESO, y del que se hace eco el profesorado de la investigación, se trata de la elección temprana de itinerario que, con la LOMCE, se adelanta de los 16 a los 15 años, aumentando la segregación escolar y social del alumnado, especialmente el que se encuentra en situación de vulnerabilidad social:

"El riesgo de abandono escolar, y abora con el tema de la FP Básica que es muy preocupante, porque yo creo que hay un enfoque que todavía es más constreñidor para ese tipo de alumno. (...) Empiezas con 15 años. Antes de terminar tu edad de Enseñanza Obligatoria ya puedes tener una opción hacia la Formación Básica sin garantías de tener sitio (...) Me preocupa el que se haya modificado tanto, tanto, tanto, tanto la normativa sin contar con nadie que cuesta trabajo encontrar el significado que tienen los cambios». (G4H5).

Por tanto, el profesorado de la investigación se muestra consciente de cómo las reformas educativas van asentando una cultura de la evaluación y la rendición de cuentas, con la consecuencia de introducir cambios importantes en torno a la profesionalidad docente, así como sobre el alumnado, siendo fundamental el contexto en que todo ello se lleva a cabo (Mons, 2009).

\subsection{El profesorado frente a la rendición de cuentas}

El tercer aspecto presente en los discursos docentes analizados es su propia situación, emergente precisamente a partir de la implantación de esas políticas de rendición de cuentas del trabajo docente. La figura 4 muestra las subcategorías en que se dividen los datos de la investigación en este aspecto. Cabe señalar aquí que los tres aspectos o dimensiones analizados en este artículo están estrechamente imbricados entre sí en los discursos del profesorado de la investigación al analizar las políticas de rendición de cuentas en España y, más concretamente, la LOMCE en el momento de su implantación en Secundaria. Sin embargo, para sistematizar el análisis que se realiza en este artículo, se ha procedido a una categorización más fina que nos permita entender mejor las múltiples dimensiones implicadas en la implementación del accountability en España y lo que ello significa para el profesorado de Secundaria. En este apartado 3, damos cuenta, pues, de esa variedad de cuestiones educativas relacionadas en España con la rendición de cuentas, al menos desde la perspectiva del profesorado de nuestra investigación. 


\section{Figura 4. Subcategorías relativas al profesorado de Secundaria en España frente a la rendición de cuentas}

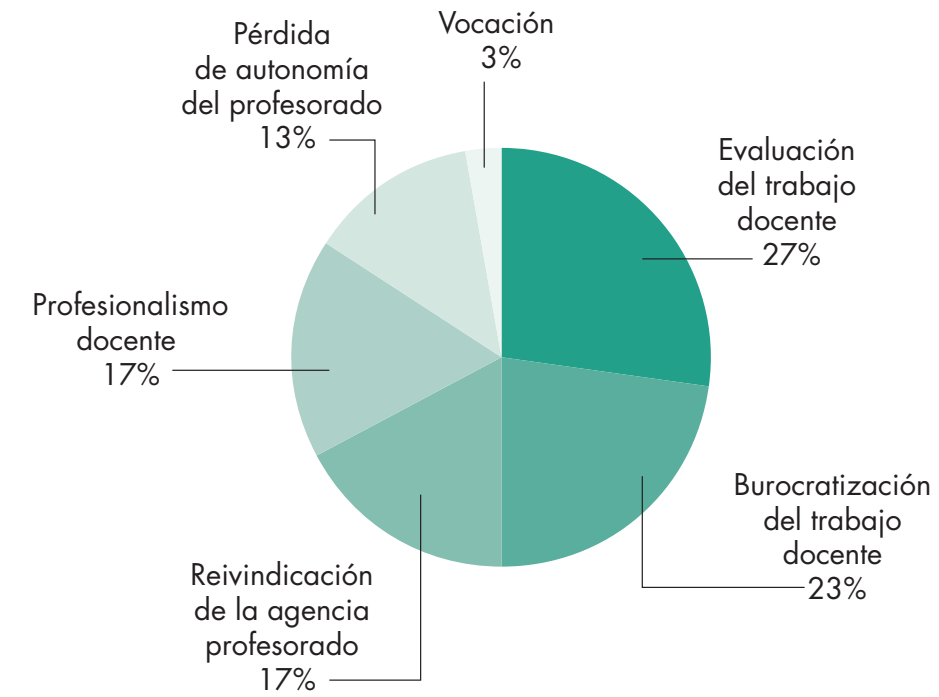

Fuente: Elaboración propia.

Para analizar los datos, resulta imprescindible diferenciar al profesorado de la investigación entre el colectivo funcionario y el laboral. En España, uno de los principales argumentos que justifica la necesidad de imputabilidad del trabajo docente es la acomodación del colectivo funcionario, cuya representación en el imaginario social es la un sujeto que, una vez que ha ganado su plaza en concurso público y competitivo, y sabiendo que su puesto de trabajo es vitalicio, se acomoda a él y reivindica sus derechos laborales, a cambio de un nivel de esfuerzo y rendimiento mínimo:

«En la pública, el que es funcionario, se ha sacado la plaza y, aqui arda Troya, que me tengo que tomar el café del recreo». (G10H2).

De ahí que muchas voces, críticas con la condición funcionarial del empleo público, apoyen la necesidad de que el profesorado rinda cuentas de su trabajo. Para quienes muestran un mayor compromiso con lo público, la necesidad de rendir cuentas radica en que empleo y sueldo funcionariales son públicos. Por su parte, el profesorado de la investigación se muestra consciente de que los cambios en torno a su condición funcionarial, intocable, han venido para quedarse. De hecho, forman parte de cambios estructurales más profundos que redefinen el profesionalismo docente (Whitty, 2000; Evetts, 2006, 2011; Hall y MacGinity, 2015; Dutercq y Maroy, 2017):

"Obviamente, esto no va a ser asi siempre. Yo estoy seguro que esto va a cambiar y que aquel profesor que no sea capaz de sacrificar su café para tomar una medida educativa con sus alumnos no va a estar ahi. No sé cuánto vamos a tardar, ¿eh?, igual no lo vemos nosotros». (G10H2).

Haciendo bandera de las críticas sociales contra la acomodación funcionarial, el gobierno del Partido Popular, al llegar al Ministerio en 2011, no solo promovió la reforma educativa hacia la LOMCE (2013), sino que introdujo con firmeza los estándares de aprendizaje arriba analizados, así como dispositivos más directos para la evaluación del profesorado ${ }^{10}$ que, por el momento, parecen haber quedado en un cajón:

10 Para ello, encargó el «Libro Blanco sobre la Profesión Docente» al catedrático de instituto José Antonio Marina, cuyos planteamientos resultaron muy polémicos entre el profesorado, como se observa también en estos grupos de discusión. 
«G9H3: una de las dificultades que yo creo que hay a nivel sociológico, a nivel politico y demás, es cómo diablos medir lo que hay en Educación. Ahora que según el experto éste, Marina, dar unos incentivos a los profesores que tengan mejores resultados... ¿Pero cuáles son los mejores resultados? ¿En qué sentido se miden? ¿Cómo se mide a un profesor verdaderamente? Yo lo veo muy difícil, ¿eh? Muy difícil.

G9M1: Y qué es un mejor resultado.

G9M2: Marina, perdón, (...) ba metido la mecha (...) supongo que tendrá también más ventas, ¿verdad?, en el libro que ha escrito nuevo. Pero dice: "Tú tienes que ser la que digas que tu compañero tiene que irse del centro porque no es válido". Eso es la mayor barbaridad que se ha dicho en Educación».

A diferencia del profesorado funcionario, los datos de la investigación muestran que la rendición de cuentas del trabajo docente es especialmente contundente en los centros privados concertados y, sobre todo, privados, donde se utilizan dispositivos como las encuestas de satisfacción del alumnado con el trabajo del profesorado, o agentes externos al centro que entran en el aula para observar (evaluar) a cada docente, siguiendo un modelo fuertemente clientelar:

"Cada curso, los 180-170 alumnos que tengo, les pasan una encuesta de no sé cuántas preguntas el jefe de departamento, el jefe de estudios. Que además quieren meter a un par de sujetos extraños abí en el aula, que también se meten. Aqui estamos, por lo que sea... Hay tantas variables. ¿Y te pueden juzgar la labor de todo un año por una clase, o cómo es esto?». (G11H2).

El profesorado de la investigación que trabaja en estos centros construye un discurso que lo muestra especialmente expuesto, y vulnerable laboralmente:

«Nosotros somos ahora mismo yo creo que el colectivo más sacrificado que hay de todos los trabajadores de la sociedad. Somos los más sacrificados, te lo digo de verdad, porque encima de que te exigen una serie de valores estamos bajo la lupa». (G2M3).

También hay en la investigación quien recuerda que el trabajo docente, y los resultados de este trabajo, han estado siempre expuestos ya que el profesorado desarrolla su labor frente al alumnado, las familias, la dirección del centro, etc.:

«Es que nosotros presentamos nuestro trabajo ante otras personas. (...) nuestra labor se valora por agente externos. Nosotros tenemos que llevar alumnos bien formados en todos los aspectos, pero también académicamente. Entonces, claro, alguien de fuera va a valorar nuestra labor». (G9M5).

Sin embargo, en términos generales, el profesorado de la investigación es consciente de que los cambios en las políticas educativas conllevan un cambio también en el trabajo docente en términos de un incremento de la rendición de cuentas sobre los resultados de ese trabajo, que se miden a través de pruebas estandarizadas ${ }^{11}$ :

11 Este aspecto es uno de lo fenómenos centrales del análisis que plantea este monográfico. 
«Estamos en el medio, por una parte, tienes que desarrollar una forma de trabajar diferente pero, por otra parte, te miden por resultados, y los resultados se miden en un examen clásico (...) la Selectividad, ahora las famosas pruebas que quieren poner». (G3M1).

Incluso, hay quien va aceptando ya la lógica de la rendición de cuentas del trabajo docente, a pesar de las reticencias y la falta de hábito en el seno de la profesión docente:

«No estamos habituados. Yo sé que en la educación, en cualquier sector, hay que fiscalizar más, a ver, qué has hecho, cómo lo has hecho, por qué lo has hecho y cuándo lo has hecho... A nosotros nos cuesta». (G3H2).

El segundo aspecto más citado en este bloque relativo al profesorado es la burocratización del trabajo docente. Esa burocratización se concreta a dos niveles, según los datos de la investigación. Por un lado, a un nivel organizacional, en la falta de concreción de la legislación educativa, que ya se ha comentado con anterioridad en este artículo, y que impide al profesorado una toma de decisiones basada en criterios claramente definidos desde la administración educativa:

"Yo tuve un alumno que cumplía los 18. El padre se empeñó en hacer una segunda repetición de $4^{\circ}$ de la ESO y superaba..., iba a superar los 19. Como la Ley no está clara y le pregunté a varios orientadores, (...) cada uno decía una cosa. (...) Llamo al inspector, le comento y me dice: "Sí, sí. No hay ningún problema. Que se matricule y si saca el curso pues lo ba sacado aunque tenga 19 años". Como me han pasado muchas cosas en esta vida pues llamé a otro, y lógicamente me dijo lo contrario: "Imposible. ¿Cómo va a estar en $4^{\circ}$ de la ESO con 19 años?". Le mandé un escrito a la Consejería, a la Inspección. ¿Sabéis lo que me contestó? Que me atuviera a la legislación vigente». (G4H5).

El segundo nivel se refiere a la propia burocratización de las prácticas educativas del profesorado, que se van alejando del trabajo educativo per se para aproximarse a un trabajo administrativo más propio de otras profesiones que de la docente:

«Estamos viendo que, por un lado, las leyes nos están cada vez diciendo que hagamos más cosas, más cosas. Los profesores nos convertimos más cada vez en burócratas: mucho papeleo, muchas programaciones, muchos estándares, muchas cosas. Yo lo veo todos los días: los profesores están ya hasta las narices. (...) Si lo importante es dar clase a nuestros alumnos y resulta que llego a mi casa y no preparar tranquilamente un examen, me tengo que poner a bacer cien mil papeleos. (...) queremos tener leyes como los países más avanzados según el Informe PIS A, pero luego no damos medios (...) tenemos una enseñanza de burócratas». (G4H1).

"Las leyes cada vez, nos traen más papeleo, y programaciones, y estándares de aprendizaje, y tal. Pues nos convertimos en máquinas de generar documentación que yo no sé quién lee». (G9H1).

Una de las consecuencias más destacadas sobre el profesorado de los procesos de cambio que estamos analizando en este artículo es la pérdida de autonomía de su trabajo como profesional, en la medida en que su trabajo se va definiendo cada vez más por instancias externas y/o ajenas a sí mismo, de manera que el profesorado de la investigación da muestras de sentir que va perdiendo cada vez más el control de su propio trabajo, de las decisiones que implica, de las tareas y los tiempos, los objetivos, los contenidos, etc.: 
"La legislación nos va marcando mucho la pauta del camino a seguir. (...) a veces tenemos una mochila muy pesada que se llama pruebas externas, que se llama pruebas de acceso a selectividad, a universidades, que nos pautan mucho la forma de trabajar. (...) Y el profesorado, en general, entiende que no tenemos horas suficientes para abordar todo lo bien que nos gustaría los diferentes aspectos de esa educación integral. (...) ese currículum te viene dado de entes superiores». (G10H2)

«G8M2: Yo entiendo que esta ley [la LOMCE] eso, te constriñe más, te limita a la hora de poder tomar tú, como docente, como profesor, ese tipo de decisiones de ser un curriculum un poco más flexible. ¿Vale? No ya porque lo justifiques delante de la... del este de calidad del ISO 2000 o delante de inspección. No es que lo justifique yo abi...

G8H3: Mira, que esto no puede sern.

Es fácil entender que, como resultado de todo ello, el profesorado de la investigación se reivindique como agente en el marco de estos cambios (Venegas, 2017b), es decir, que se reivindique como sujeto político con capacidad de actuar en los cambios educativos, sobre todo por ser uno de los protagonistas principales de los fenómenos implicados en esos procesos de cambio, frente a agentes externos que, de nuevo, minan la autonomía y capacidad de agencia del profesorado, lo que podemos entender como una estrategia de resistencia frente a los cambios que conducen hacia la desprofesionalización del profesorado:

"Las leyes son papeles. Entonces, los que producen los cambios son los profesores y las profesoras. Y si no cambiamos abi, pues no cambiamos el sistema». (G10M3).

"La legislación mejoraría mucho si el profesorado twiera un papel un poco más activo en la elaboración de las leyes y no (...) los legisladores, que son como una gente un poco externa, que no saben lo que se cuece en el aula». (G10H1).

"Creo que han estado un poco de espaldas a nosotros y, muchas veces, o en la mayoría de los casos, legislando sin pensar en qué podemos opinar, o en pedirnos un poco opinión, ¿no?»). (G5H2).

Por tanto, los discursos del profesorado de esta investigación se mueven entre dos grandes tendencias en relación al profesionalismo docente. Una primera, que mira hacia atrás, anclada en la vieja creencia en la vocación docente, mayoritaria entre el profesorado de la investigación, y que entiende el trabajo docente como orientado por una especie de don natural:

"Yo creo que tiene que ver mucho la vocación famosa. Debería de ser una vocación muy trabajada y muy vinculada a analizar ese carácter y a darnos trucos y pautas para qué hacer en el aula». (G10H3).

La vocación no necesita, pues, formación, solo algunos trucos y pautas, «recetas», pues existe la creencia de que «los que no son vocacionales son los que más problemas tienen en el aula» (G8H1). La vocación es la esencia que explica el ser docente, aún cuando se está sufriendo el deterioro del trabajo docente analizado más arriba:

«Yo, cuando empecé en la enseñanza era, en cierto modo, (...) un chollo (...) pero cada vez, hemos ido perdiendo privilegios, por decirlo de alguna manera, y hoy ya no es tan chollo el dedicarse a esto, ¿no? $Y$ uno lo bace por vocación». (G8H2). 
La segunda gran tendencia entre el profesorado de la investigación, claramente minoritaria, pone en cuestión duramente esa idea de vocación: «A mi me da un poco miedo la palabra vocación, a veces, porque es como que el profesor hace voluntariado» (G11M1), y reivindica el trabajo docente como profesión:

«G11H1: Yo siempre digo que la vocación es para los curas.

(...)

Yo soy un profesional.

(...)

G11M1: Yo era vocacional y me profesionalicé. Yo al principio decía "sí, yo quiero dar clase, me encanta, tal". Y luego me di cuenta de que era una película tener vocación. Es que no tiene sentido. Es que además te frustran la vocación. (...) Ya está, profesionalización. Y, además, he trabajado con mucha gente que era profesional, no tenia vocación y trabajaba súper bien. Dije: "¿para qué sirve la vocación?". No creo en la vocación en la enseñanzà.

Esta tendencia, minoritaria entre el profesorado de la investigación, demanda una mayor profesionalización del profesorado, pues parece entenderla como estrategia de resistencia frente a los cambios en la profesión docente que se analizan en este artículo:

«Creo que lo único que podemos mejorar es la profesionalidad del profesorado. Deberiamos de ser más competentes. Yo tengo claramente compañeros incompetentes que están dando clase y que no superarían una evaluación normal de oposición. En ese sentido, yo ya reclamaría que lo unico que podemos hacer, internamente, es mejorar como profesores, en base seguramente a evaluaciones. (...) Creo que es el profesional el que debe ser mucho más profesional. Y se le debe de evaluar. (...) yo creo que nosotros hacemos lo que podemos, que quizás no es mucho pero... (...) Creo que cambiarlo todo no se puede cambiar y lo unico que se puede reclamar es a las personas más responsabilidad». (G10H3).

Esta última cita concluye apuntando hacia un fenómeno emergente entre el profesorado español de Secundaria: la internalización del discurso dominante en las políticas de rendición de cuentas sobre la responsabilización social del profesorado en aquellos contextos donde, por sus condiciones estructurales y su modelo social y de bienestar, los dispositivos de rendición de cuentas son aún 'suaves' (Maroy y Voisin, 2013), pero se apuesta, de manera contundente y creciente, por la evaluación del trabajo docente.

Por su parte, la literatura especializada señala un proceso de desprofesionalización progresiva del profesorado, que podríamos observar también en el caso español. Concluimos este artículo, a continuación, discutiendo algunas ideas que pueden enriquecer el debate en España en torno al fenómeno aquí analizado.

\section{Discusión de los resultados y conclusiones}

El objetivo de este artículo ha sido analizar los discursos del profesorado de ESO sobre las políticas de rendición de cuentas del trabajo docente en España, para lo que analiza los discursos emergentes en 10 grupos de discusión con un total de 63 docentes. El análisis nos permite llegar a las siguientes conclusiones. 
Tal vez sea válido para España, en términos generales, lo que plantea Dutercq (2016) para el caso francés: que las medidas introducidas en el país atañen poco al personal de los centros educativos, que sigue trabajando bajo un régimen de responsabilidad moral y profesional más que gerencial y, en el caso español, con una creencia elevada aún en la vocación como principio docente. Siendo esto válido como situación estructural de las políticas de rendición de cuentas en España en el momento actual, merece la pena atender a los datos procedentes de nuestra investigación para conocer las tendencias de cambio que se observan en los discursos del profesorado.

En primer lugar, a un nivel mesosociológico de análisis, el profesorado señala unánimemente la inestabilidad de las políticas educativas en España cada vez que hay un cambio de gobierno estatal (De Puelles, 2016). A priori, todo el profesorado considera que esos cambios son sólo de orden discursivo (político) (véase también Dutercq, 2016), pero no generan un cambio ni estructural (en la organización de los centros), ni en las prácticas docentes, debido a tres posibles factores que apunta:

- una ejecución top-down imperfecta de las políticas educativas;

- la tendencia del sistema educativo a reproducirse;

- o la falta de recursos destinados a educación.

Los datos muestran que el profesorado responde con una estrategia de acomodación intermedia, a caballo entre la nueva legislación y lo que hacían con anterioridad, tanto a los cambios de política educativa, en general, cuanto, más concretamente, a la evaluación estandarizada introducida por la LOMCE para evaluar al alumnado, lo que muestra cierta relación con la conformidad analizada por Hall y MacGinity (2015) entre el profesorado de su estudio, tal vez no tanto por la necesidad de mantener una identidad profesional viable frente al neoliberalismo, como en su estudio, cuanto por la falta de especificación topdown del cambio legislativo desde la administración educativa hacia las prácticas docentes, como se queja el profesorado de nuestra investigación.

Este desconcierto nos lleva a la segunda conclusión del artículo: aunque, a priori, el discurso docente no reconoce un impacto directo de la reforma educativa sobre la organización de los centros y las prácticas docentes, una aproximación más detallada a sus discursos muestra que la política de rendición de cuentas del trabajo docente y la evaluación mediante estándares de aprendizaje impuestas por la LOMCE, introducen modificaciones importantes sobre la profesionalidad docente (Maroy, 2006) también en España, como ocurre en otros países. Muestra de ello son los efectos perversos derivados de esta Policy evaluation (Mons, 2009) -concretamente el «testing»- que señala el profesorado de la investigación: el «teaching to the test» y, con ello, la reducción del currículum escolar (Mons, 2009; Yerly, 2017; Maroy et al., en este monográfico). Frente a ello, buena parte del profesorado reivindica la dimensión humana presente en la relación docente de enseñanza-aprendizaje, que escapa a la medición estandarizada, y un grupo minoritario rechaza esta centralidad creciente de la filosofía de la evaluación (Martuccelli, 2010) por homogeneizar la producción de sujetos escolares. Por tanto, este análisis más minucioso deja ver que, frente a la impresión apriorística del profesorado sobre la reproducción del sistema y las prácticas educativas, a pesar de las reformas, existe un impacto destacable de éstas, con especial atención a la LOMCE, sobre sus prácticas docentes y la organización de sus centros: la consolidación creciente de una cultura de la evaluación (Ruiz, 2010), cuyo principal mecanismo de regulación educativa son los dispositivos de rendición de cuentas (Ranson, 2003; Mons, 2009; Ruiz, 2010; Cattonar, Dumay y Maroy, 2013; Maroy y 
Voisin, 2013; Dutercq, 2016; Dutercq y Maroy, 2017; Yerly, 2017), todo lo cual introduce cambios sobre la profesionalidad docente (Maroy, 2006) y para el alumnado (Mons, 2009).

La tercera conclusión del artículo se refiere al impacto de las políticas de rendición de cuentas sobre el profesorado. Los datos de la investigación diferencian entre profesorado funcionario, de centros públicos, y profesorado laboral, de centros privados y concertados. El discurso que cuestiona la inmunidad del funcionariado ha calado socialmente en España, lo que podría apuntar hacia el desmantelamiento progresivo del empleo funcionarial en la administración pública, en el marco de una nueva gobernanza, neoliberal (Ranson, 2003), basada en la evaluación (Martuccelli, 2010). El profesorado de la investigación parece consciente de esta tendencia que, por otro lado, forma parte, como hemos dicho antes, de cambios estructurales más profundos que redefinen el profesionalismo en general (Evetts, 2006, 2011), y el docente en particular (Whitty, 2000; Maroy y Cattonar, 2012; Luengo y Saura, 2013; Hall y MacGinity, 2015; Dutercq y Maroy, 2017; Venegas, 2017a). Otros aspectos destacados están implicados en ello, como la burocratización del trabajo docente (Evetts, 2006, 2011), que los datos de nuestra investigación sitúan en dos niveles, el organizacional, relativo a la falta de claridad de las políticas educativas, y el de la práctica docente, definida por un trabajo cada vez menos educativo y más administrativo. La consecuencia es la pérdida de autonomía del profesorado (Cattonar y Maroy, 2012; Maubant, Roger y Lejeune, 2013; PerezRoux y Maleyrot, 2015), que da lugar a, y es consecuencia de, la desprofesionalización del trabajo docente (Maroy, 2006; Cattonar y Maroy, 2012; Maubant, Roger y Lejeune, 2013; Perez-Roux y Maleyrot, 2015). En este sentido, la estrategia del profesorado es una resistencia que toma la forma de reivindicación de su agencia como sujeto político que ha de formar parte activa en los procesos educativos, frente a la negación de su agencia que supone la rendición de cuentas burocratizada (Ranson, 2003), una ausencia del profesorado señalada también por Maroy (2006). Así, el profesorado de la investigación se mueve entre la vieja idea de vocación y la reivindicación de profesionalización (véase también Maroy, 2006), en medio de estas tendencias desprofesionalizadoras fruto de las políticas neoliberales propias del NPM (Ball, 2003), con especial atención a las políticas de rendición de cuentas, y que van siendo internalizadas por una parte del profesorado en términos de responsabilidad social del trabajo docente, dando así contenido a una 'subjetivación' (Venegas, 2017b) profesional neoliberal (en esta línea, véanse Ball, 2003, 2015; Luengo y Saura, 2013) que, si bien se apunta en los discursos del profesorado, necesitaría de otra técnica más adecuada para ello, como la entrevista, pero que, sin duda, nos abre una futura línea de investigación partiendo de las conclusiones de ésta.

\section{Referencias bibliográficas}

Ball, Stephen J. (2003): “The teacher's soul and the terrors of performativity". Journal of Education Policy, 18 (2), 215-228, http://dx.doi.org/10.1080/0268093022000043065

Ball, Stephen J. (2015): “Subjectivity as a site of struggle: refusing neoliberalism?”. British Journal of Sociology of Education. doi: 10.1080/01425692.2015.1044072

Bonal, Xavier (2014). “La LOMCE como consolidación del Thatcherismo educativo". eldiario.es (14.09.2014), en http://www.eldiario.es/agendapublica/impacto_social/LOMCE-consolidacionThatcherismo-educativo_0_302370453.html

Bonal, Xavier y Verger, Antoni (2016): Monográfico "Privatización educativa y globalización”. Revista de la Asociación de Sociología de la Educación, 9 (2), https://ojs.uv.es/index.php/RASE/issue/view/641/ showToc 
Cattonar, Branka; Dumay, Xavier y Maroy, Christian (2013): "Politique d'évaluation externe et recomposition des professionnalités dans l'enseignement primaire: un cas de responsabilisation (accountability) douce". Education et sociétés, 2(32), 35-51. doi: 10.3917/es.032.0035

De Puelles, Manuel (2016): "Reflexiones sobre cuarenta años de educación en España o la irresistible seducción de las leyes". Historia y Memoria de la Educación, 3, 15-44.

Dubet, François y Martuccelli, Danilo (1998). En la escuela. Sociología de la experiencia escolar. Buenos Aires: Losada.

Dutercq, Yves (2016): “Accountability, una caja de herramientas, no una política: el caso del sistema educativo francés". Profesorado. Revista de Currículum y Formación de Profesorado, 20 (3), 145-169.

Dutercq, Yves y Maroy, Christian (2017). "Le travail et le professionnalisme enseignants face aux politiques de responsabilisation: introduction à la problématique" en Christian Maroy e Yves Dutercq (dtrs.). Le travail et le professionnalisme enseignants face aux politiques de responsabilisation. Louvain-la-Neuve : De Boeck.

Evetts, Julia (2006): "Short Note: the Scoiology of Professional Groups". Current Sociology, 54 (1), 133 143.

Evetts, Julia (2011): “New Professionalism? Challenges and Opportunities”. Current Sociology, 59 (4), 406422.

Feito, Rafael (2017): “¿Qué dice la investigación social sobre las pruebas educativas externas?”. Revista Internacional de Sociología, 75 (1), 1-11, http://dx.doi.org/10.3989/ris.2017.75.1.15.89

Hall, David y McGinity, Ruth (2015). "Conceptualizing teacher professional identity in neoliberal times: Resistance, compliance and reform". Education Policy Analysis Archives, 23 (88), 4-21, http://dx.doi. org/10.14507/epaa.v23.2092

Jefatura del Estado, LOE, Ley Orgánica 2/2006, de 3 de mayo, de Educación, BOE Núm. 106, jueves, 4 de mayo de 2006, http://www.boe.es/boe/dias/2006/05/04/pdfs/A17158-17207.pdf

Jefatura del Estado, LOMCE, Ley Orgánica 8/2013, de 9 de diciembre, para la Mejora de la Calidad Educativa, BOE Núm. 295, martes, 10 de diciembre de 2013, https:/ /www.boe.es/boe/dias/2013/12/10/ pdfs/BOE-A-2013-12886.pdf

López, Francisco (2013). "Profesión y formación del profesorado de Secundaria”. Conferencia en el Congreso Internacional Euro-Iberoamericano sobre la formación del profesorado de educación secundaria. Reflexión, análisis y propuestas. Madrid, 16-19 de julio.

Luego, Julián y Saura, Geo (2013): "La performatividad en la educación. La construcción del nuevo docente y el nuevo gestor performativo”. REICE, 11 (3), 139-153.

Maubant, Philippe; Roger, Lucie y Lejeune, Michel (2013): “Déprofessionnalisation”. Recherche et formation, 72, 89-102, doi: $10.4000 /$ rechercheformation.2041

Maroy, Christian (2006): "Les évolutions du travail enseignant en France et en Europe: facteurs de changement, incidences et résistances dans l'enseignement secondaire”. Revue Française de Pédagogie, 155 (2), 1-32. 
Maroy, Christian (2008): "Vers une régulation post-bureaucratique des systèmes d'enseignement ?". Sociologie et Sociétés, $40(1), 31-54$.

Maroy, Christian y Cattonar, Branka (2012): "Professionnalisation ou Déprofessionnalisation ? Le cas de la Communauté française de Belgique”. RASE, 5(3), 394-423.

Maroy, Christian y Voisin, Annelise (2013): “Les transformations récentes des politiques d'accountability en éducation: enjeux et incidences des outils d'action publique”. Educação \& Sociedade, 34 (124), 881901.

Martínez, Ignacio (2014): "La incidencia de la LOMCE y su desarrollo en las actuaciones de la inspección de educación”. Revista Supervisión, 21, 32, 1-12.

Martuccelli, Danilo (2010): “Critique de la philosophie de l'évaluation”, Cahiers Internationaux de Sociologie, 1 (128-129), 27-52. doi: 10.3917/ cis.128.0027

Mons, Nathalie (2009): “Effets théoriques et réels des politiques d'évaluation standardisée”. Revue Française de Pédagogie, 169, 99-140; doi: 10.4000/rfp.1531

Perez-Roux, Thérèse et Maleyrot, Eric (2015): "L'accompagnement des enseignants à l'heure des réformes: stratégies des formateurs de terrain face à de nouvelles formes de (dé)professionnalisation". Éducation et socialisation [En ligne], 38, doi: 10.4000/edso.1294

Ranson, Stewart (2003): "Public accountability in the age of neo-liberal governance". Journal of Education Policy, 18 (5), 459-480, doi: 10.1080/0268093032000124848

Ruiz, Ferrán (2010): "Los centros educativos ante la rendición de cuentas: 'lessons from America”. Organización y gestión educativa: Revista del Fórum Europeo de Administradores de la Educación, 18 (5), 14-17.

Venegas, Mar (2017a). "Le travail d'orientation des enseignant(e)s: une pratique éducative de responsabilisation sociale?" en Yves Dutercq y Christian Maroy (dtrs.). Professionnalisme enseignant et politiques de responsabilisation. Louvain-la-Neuve: De Boeck

Venegas, Mar (2017b): "Devenir sujeto. Una aproximación sociológica”. Convergencia. Revista de Ciencias Sociales, 73 (1), 13-36.

Whitty, Geoff (2000): “Teacher professionalism in new times”. Journal of In-Service Education, 26 (2), 281295. doi: $10.1080 / 13674580000200121$

Yerly, Gonzague (2017). “Quel est l'impact «réel» des politiques de responsabilisation douce sur les pratiques enseignantes? Analyse des effets d'un dispositif d'évaluation externe des acquis des élèves", en Yves Dutercq y Christian Maroy (dtrs.). Professionnalisme enseignant et politiques de responsabilisation. Louvain-la-Neuve : De Boeck, 121-157. 


\section{Notas biográficas}

Mar Venegas es Doctora en Sociología con Mención Europea. Profesora del Departamento de Sociología de la Universidad del Granada del que es, actualmente, Subdirectora. Ha sido Secretaria de la Asociación de Sociología de la Educación de España. Su docencia se desarrolla en el ámbito de la Sociología de la Educación, así como su investigación, en la que destacan dos grandes líneas: la Sociología de la Educación, el Género y la Sexualidad (la política afectivosexual); y la Sociología del Profesorado.

Elisa Usategui Basozabal es Doctora en Filosofía. Profesora del departamento de Sociología y Trabajo social de la Universidad del País Vasco. Su labor investigadora trata los problemas de cohesión social suscitados por los procesos de individualización y globalización que marcan las sociedades de la posmodernidad, centrándose, de modo especial en el campo de la cultura y la educación. Otra área de trabajo la conforma el análisis de los aportes de la teoría feminista a la reflexión y a la epistemología sociológica. En este sentido, ha revisado desde una perspectiva de género los diversos paradigmas y autores dentro del campo de la Teoría sociológica.

Ana Irene del Valle Loroño es Doctora en Sociología y profesora del Departamento de Sociología y Trabajo Social de la Universidad del País Vasco. Su labor investigadora se centra en el análisis de los procesos, relaciones y estructuras sociales emergentes en la familia y la educación, especialmente en lo que concierne a los valores y al cambio sociocultural, y primando la perspectiva de género. 


\section{Anexo}

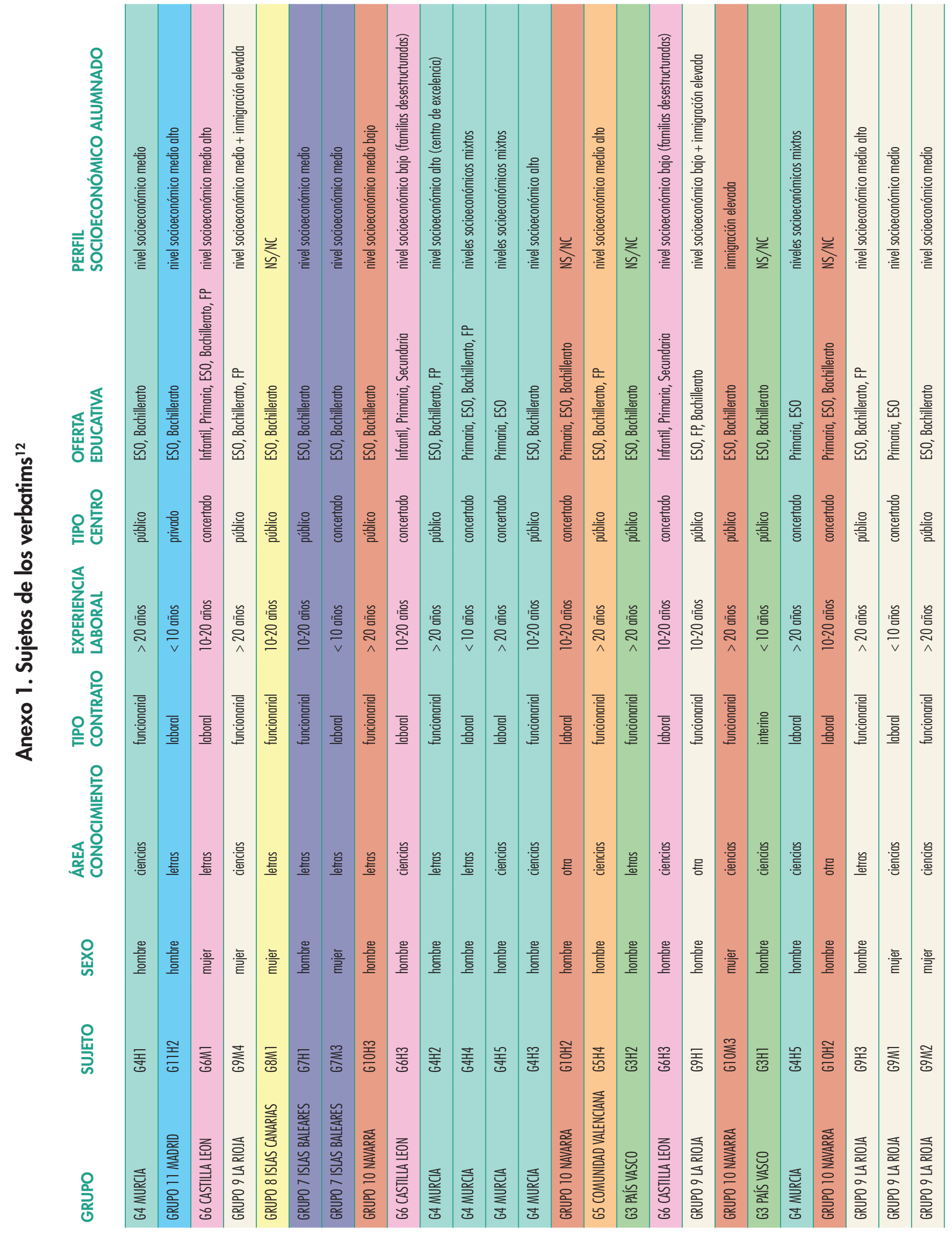




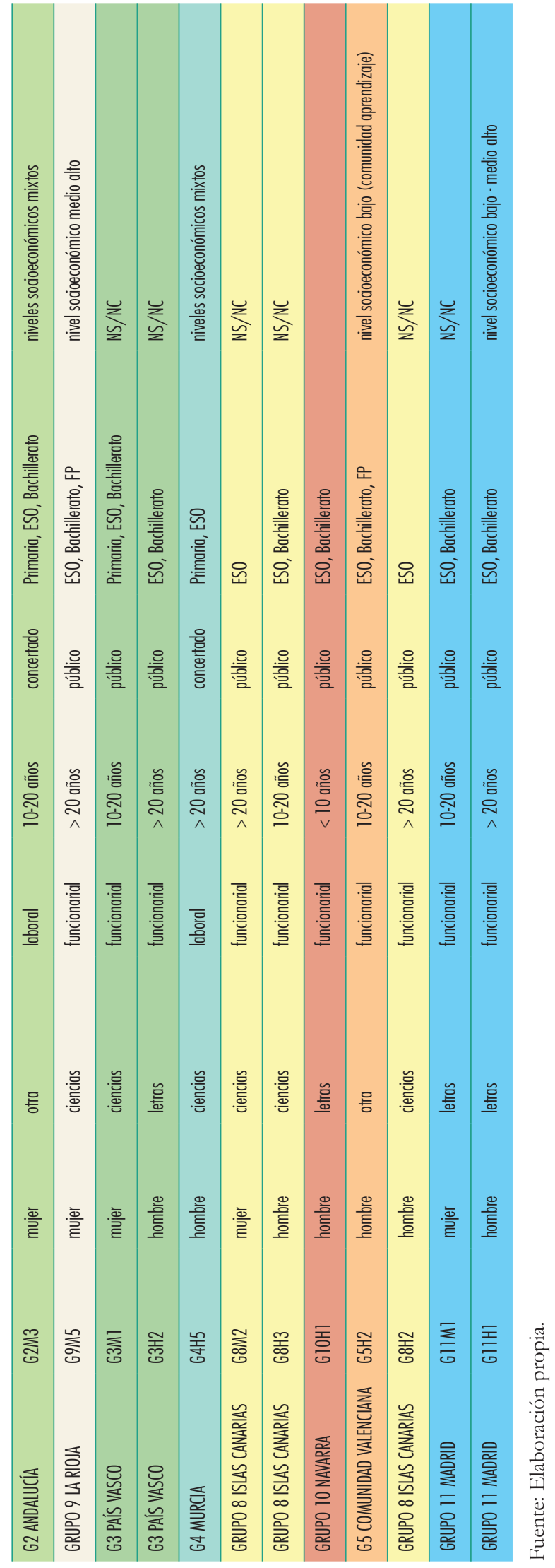

